\title{
Genetic parameters and mapping quantitative trait loci associated with tibia traits in broilers
}

\author{
B.N.N. Ragognetti', N.B. Stafuzza', T.B.R. Silva', T.C.S. Chud', N.V. Grupioni', \\ V.A.R. Cruz ${ }^{1}$, J.O. Peixoto ${ }^{3}$, K. Nones ${ }^{2}$, M.C. Ledur ${ }^{3}$ and D.P. Munari ${ }^{1}$ \\ 1'Departamento de Ciências Exatas, Faculdade de Ciências Agrárias e Veterinárias, \\ Universidade Estadual Paulista, Jaboticabal, SP, Brasil \\ 'Laboratório de Biotecnologia Animal, \\ Escola Superior de Agricultura "Luiz de Queiroz", Universidade de São Paulo, \\ Piracicaba, SP, Brasil \\ ${ }^{3}$ Embrapa Suínos e Aves, Concórdia, SC, Brasil \\ Corresponding author: D.P. Munari \\ E-mail: danisio@fcav.unesp.br \\ Genet. Mol. Res. 14 (4): 17544-17554 (2015) \\ Received April 1, 2015 \\ Accepted September 3, 2015 \\ Published December 21, 2015 \\ DOI http://dx.doi.org/10.4238/2015.December.21.27
}

ABSTRACT. Selection among broilers for performance traits is resulting in locomotion problems and bone disorders, once skeletal structure is not strong enough to support body weight in broilers with high growth rates. In this study, genetic parameters were estimated for body weight at 42 days of age (BW42), and tibia traits (length, width, and weight) in a population of broiler chickens. Quantitative trait loci (QTL) were identified for tibia traits to expand our knowledge of the genetic architecture of the broiler population. Genetic correlations ranged from $0.56 \pm 0.18$ (between tibia length and BW42) to $0.89 \pm 0.06$ (between tibia width and weight), suggesting that these traits are either controlled by pleiotropic genes or by genes that are in linkage disequilibrium. For QTL mapping, the genome was scanned with 127 microsatellites, representing a coverage of $2630 \mathrm{cM}$. Eight QTL were mapped on Gallus gallus chromosomes (GGA): GGA1, GGA4, GGA6, GGA13, and GGA24. The QTL regions for tibia length and weight were mapped on GGA1, between LEI0079 and MCW145 markers. The gene 
$D A C H 1$ is located in this region; this gene acts to form the apical ectodermal ridge, responsible for limb development. Body weight at 42 days of age was included in the model as a covariate for selection effect of bone traits. Two QTL were found for tibia weight on GGA2 and GGA4, and one for tibia width on GGA3. Information originating from these QTL will assist in the search for candidate genes for these bone traits in future studies.

Key words: Gallus gallus; Broiler chicken; Genotyping; Heritability; Microsatellite; Quantitative trait loci mapping

\section{INTRODUCTION}

For over half a century, broiler breeding programs have focused mainly on improving important production traits, such as growth rate and feeding efficiency (Le Bihan Duval et al., 2011). According to Knowles et al. (2008), broiler growth rate has increased by $300 \%$ in the last 60 years. However, bone structure is not strong enough to support body weight in broilers with high growth rates (Bradshaw et al., 2002). Bone disorders in broiler lines result from intense selection for fast growth (Havenstein et al., 1994a; 1994b), which may have favored the elimination of alleles that influence bone structure, strength, and composition, resulting in disorders of bone metabolism.

Reis et al. (2011) demonstrated that fast bone growth caused by rapid weight gain does not allow bone tissue to form properly, resulting in low mechanical performance and less resistant and rigid bones. Breeding programs have focused on improving bone integrity traits, due to economic losses in the poultry industry such as reduced economic return from carcasses with lesions resulting from high body weight with low bone strength. Bone integrity traits are highly relevant to the poultry agroindustry; however, these traits are difficult to measure. The use of advanced techniques for genome studies can be an effective alternative in order to decrease skeletal problems in heavy broilers. Quantitative trait loci (QTL) mapping is one of the major approaches in molecular genetic studies for detecting genetic variability of economically important traits (Zhang et al., 2011). Mapping studies have identified regions in the chicken genome that contribute to characterization of genetic variation, thus allowing mapping of candidate genes.

The majority of QTL previously mapped for growth traits were associated with body weight and carcass composition (Gao et al., 2011). Some authors have mapped QTL for bone traits (Schreiweis et al., 2005; Sharman et al., 2007), such as tibia and femur length (Tsudzuki et al., 2007; Zhou et al., 2007; Gao et al., 2010). According to Araújo et al. (2012), studying traits inherent to bone structures and properties will help to improve our understanding of locomotor disorders, and provide possibilities for effective solutions. In order to better understand the genetic architecture of bone and growth traits in broiler chickens, the aim of the current study was to estimate genetic parameters and map QTL regions for body weight at 42 days of age (BW42) and tibia bone traits in an $\mathrm{F}_{2}$ chicken population (broiler $\mathrm{x}$ layer line).

\section{MATERIAL AND METHODS}

\section{Experimental population}

Chickens used in the study were an $\mathrm{F}_{2}$ population developed at the Brazilian National Research Center for Swine and Poultry (Embrapa Suínos e Aves, Brazil) from reciprocal 
crossbreeding of broiler male (TT) and layer female (CC) lines, as previously described (Nones et al., 2006; Savegnago et al., 2011). The population was designed specifically for QTL mapping studies, to obtain linkage disequilibrium and variability for performance and carcass traits (Nones et al., 2006; Ambo et al., 2009; Savegnago et al., 2011).

Chickens were reared in floor pens until 35 days of age, and were then individually caged until 41 days of age. They were offered ad libitum access to corn, soybean, and water, and a ration diet that contained $21 \%$ crude protein (CP) and $3150 \mathrm{kcal}$ metabolizable energy (ME) (1 to 21 days of age); $20 \% \mathrm{CP}$ and $3200 \mathrm{kcal}$ ME (22 to 35 days of age); and $18.5 \% \mathrm{CP}$ and $3200 \mathrm{kcal}$ ME (36 to 41 days of age). Chickens were slaughtered at 42 days of age, at which point, blood samples were collected for DNA analysis.

\section{Phenotypes and genotyping}

Body weight at 42 days of age (BW42) corresponded to live weight after $6 \mathrm{~h}$ of fasting and transportation for slaughter. Following slaughter, cartilage and muscle were removed from the tibias of each bird, which were then stored at $-20^{\circ} \mathrm{C}$ for subsequent measurements. Tibia traits were evaluated after thawing of tibia samples to room temperature. Tibia length (the distance between distal and proximal bone ends) and width in the central region of the bone were measured using a manual caliper $(0.01 \mathrm{~mm})$. Bones were weighed on an analytical balance.

DNA was extracted from blood samples $(5 \mu \mathrm{L})$ using $500 \mu \mathrm{LDNAzo}{ }^{\circledR}$ following the manufacturer instructions (Life Technologies, Gaithersburg, MD, USA). A total of 649 animals were genotyped using 127 microsatellite markers, as previously described (Nones et al., 2006; Campos et al., 2009). Genotyping was carried out using a MegaBACE automated sequencer, and fragment size analysis was performed using the Genetic Profiler software (both GE HealthCare, Little Chalfont, BKM, UK).

\section{Genetic parameters}

The least-squares method was employed to define fixed effects to be included in the mixed model, using the SAS ${ }^{\circledR}$ GLM procedure (Statistical Analysis System, v.9.3, Cary, NC, USA). The group was composed by the fixed effect of sex (male or female), and hatching (17 levels), and was statistically significant $(P<0.0001)$ for all traits (BW42; tibia length, width, and weight). Body weight at 42 days was statistically significant $(P<0.01)$ and was considered as a covariate for tibia length and width (linear and quadratic), and tibia weight (linear effect).

Genetic parameters and standard errors were estimated by restricted maximum likelihood testing under an animal model (multi-trait analyses). Analyses were conducted using the WOMBAT software (Meyer, 2007) considering the convergence criterion of $10^{-9}$. The general model included the fixed effect of group (sex-hatching) and random direct additive genetic and residual effects for all traits. The trait BW42 was also included in the model as a covariate for tibia bone traits. The mixed model used for all traits was:

$$
y=X \beta+Z a+e
$$

(Equation 1)

In Equation 1 above, $y$ is the observation vector for each trait; $\beta$ the vector of all fixed effects; $\alpha$ the vector of random direct additive genetic effects; and $\boldsymbol{e}$ the vector of random residual effects. The 
following assumptions were made:

$$
\begin{aligned}
& \operatorname{Var}(a)=A \sigma_{a}^{2} \\
& \operatorname{Var}(e)=I \sigma_{e}^{2}
\end{aligned}
$$

In Equation 2, $A$ is the relationship matrix, and $\sigma_{a}^{2}$ the variation attributed to additive genetic effects. In Equation 3, I is an identity matrix, and $\sigma_{e}^{2}$ the variation attributed to residual effects.

\section{Quantitative trait loci mapping}

Interval mapping was used to detect QTL for tibia bone traits. Analyses were performed using the GRIDQTL software (http://www.gridqtl.org.uk/index.htm; Seaton et al., 2006). Fixed effects of dam's family, sex, and hatching, as well as the BW42 covariate, were included for all traits. Chromosomal significance thresholds $(\alpha=0.05$ to 0.01$)$ were determined using GRIDQTL with 10,000 permutation tests (Churchill and Doerge, 1994).

Positions of markers flanking QTL regions were identified in base pairs according to Gallus gallus 4.0 genome assembly (NCBI database http://www.ncbi.nlm.nih.gov/ genome/?term=gallus+gallus). Identified QTL regions were individually scanned for identification of potential candidate genes associated with bone traits in broilers.

\section{RESULTS}

\section{Genetic parameters}

Phenotypic variations in tibia length, width, and weight, and in BW42 were observed through descriptive statistics (Table 1). Tibia weight and length presented, respectively, the highest $(20.75 \%)$ and lowest $(6.5 \%)$ coefficients of variation. Tables 2 and 3 show genetic parameters estimates obtained from multi-trait analyses. Heritability estimates (Table 2) ranged from $0.15 \pm$ 0.05 (BW42) to $0.32 \pm 0.09$ (tibia width). The highest genetic correlation was observed between tibia weight and width $(0.89 \pm 0.06)$; the lowest was between tibia length and width $(0.57 \pm 0.17)$. Heritability estimates, genetic and phenotypic correlations decreased when bone traits were adjusted for the covariate BW42, with the exception of tibia length (Table 3).

Table 1. Descriptive statistical analysis of tibia length, width, and weight, and body weight at 42 days of age

\begin{tabular}{|c|c|c|c|c|c|c|}
\hline Trait & $\mathrm{N}$ & Mean & SD & CV (\%) & Min & Max \\
\hline Tibia length $(\mathrm{mm})$ & 1414 & 89.83 & 4.55 & 5.06 & 52.38 & 105.87 \\
\hline Tibia width (mm) & 1414 & 6.38 & 0.56 & 8.78 & 3.83 & 8.83 \\
\hline Tibia weight (g) & 1413 & 5.93 & 1.23 & 20.75 & 1.33 & 12.35 \\
\hline BW42 (g) & 2063 & 1005.71 & 142.35 & 14.15 & 402.00 & 1688.00 \\
\hline
\end{tabular}
(BW42).

Number of animals (N), mean, standard deviation (SD), minimum (Min), and maximum (max) values, and coefficient of variation (CV). 
Table 2. Heritability estimates (diagonal), genetic correlations (above diagonal), phenotypic correlations (below diagonal) and respective standard errors for tibia length, width, and weight, and body weight at 42 days of age (BW42).

\begin{tabular}{lllll}
\hline Trait & Tibia length & Tibia width & Tibia weight & BW42 \\
\hline Tibia length $(\mathrm{mm})$ & $\mathbf{0 . 2 3} \pm \mathbf{0 . 0 8}$ & $0.57 \pm 0.17$ & $0.79 \pm 0.09$ & $0.56 \pm 0.17$ \\
Tibia width $(\mathrm{mm})$ & $0.46 \pm 0.03$ & $\mathbf{0 . 3 2} \pm \mathbf{0 . 0 9}$ & $0.89 \pm 0.06$ & $0.71 \pm 0.13$ \\
Tibia weight $(\mathrm{g})$ & $0.70 \pm 0.02$ & $0.59 \pm 0.02$ & $\mathbf{0 . 2 3} \pm \mathbf{0 . 0 7}$ & $0.75 \pm 0.11$ \\
BW42 $(\mathrm{g})$ & $0.67 \pm 0.02$ & $0.55 \pm 0.02$ & $0.65 \pm 0.02$ & $\mathbf{0 . 1 5} \pm \mathbf{0 . 0 5}$ \\
\hline
\end{tabular}

Table 3. Heritability estimates (diagonal), genetic correlations (above diagonal) and phenotypic correlations (below diagonal) and respective standard errors for tibia length, width, and weight, adjusted to body weight at 42 days of age (BW42).

\begin{tabular}{llll}
\hline Trait & Tibia length & Tibia width & Tibia weight \\
\hline Tibia length $(\mathrm{mm})$ & $0.29 \pm 0.09$ & $0.28 \pm 0.23$ & $0.64 \pm 0.15$ \\
Tibia width $(\mathrm{mm})$ & $0.13 \pm 0.04$ & $0.30 \pm 0.09$ & $0.80 \pm 0.10$ \\
Tibia weight $(\mathrm{g})$ & $0.47 \pm 0.03$ & $0.37 \pm 0.03$ & $0.21 \pm 0.07$ \\
\hline
\end{tabular}

\section{Quantitative trait loci mapping}

The majority of QTL regions (Table 4) mapped on the largest chicken chromosome, GGA1, which is $195 \mathrm{Mbp}$ in size and $16.25 \%$ of the chicken genome. Quantitative trait loci regions mapped on GGA1 and GGA4 for all three tibia bone traits, whereas QTL regions of tibia length and weight were mapped flanked by markers LEI0079-MCW145 on GGA1 (Figure 1), and MCW0240-LEI0063 on GGA4 (Figure 2; Table 4). This result was validated by high genetic correlation estimated for these traits $(0.79 \pm 0.09)$. The QTL mapped for tibia length on GGA1 (ADL150-ADL309) showed additive and dominant effects, suggesting interaction between alleles at the same locus for this trait. The QTL for tibia length was mapped on a region of GGA4 flanked by markers ROS0024 and MCW240 (Table 4).

Table 4. Position of the QTL regions identified for tibia length, width, and weight on each chromosome (GGA), F-test, flanking markers and their respective positions in base pairs (bp) and centiMorgans (cM).

\begin{tabular}{|c|c|c|c|c|c|c|}
\hline \multirow[t]{2}{*}{ Trait } & \multirow[t]{2}{*}{ GGA } & \multirow{2}{*}{$\begin{array}{c}\text { QTL } \\
\text { position }^{1}(\mathrm{cM})\end{array}$} & \multirow[t]{2}{*}{ F-ratio } & \multicolumn{2}{|c|}{ Flanking markers } & \multirow{2}{*}{$\begin{array}{l}\text { No. of genes } \\
\text { on the interval }{ }^{4}\end{array}$} \\
\hline & & & & First marker (position, bp) (position, cM) & Last marker (position, bp) (position, cM) & \\
\hline \multirow[t]{3}{*}{ Tibia length } & 1 & 126 & $8.58^{3}$ & ADL0150 $(65,124,527)(124.2)$ & ADL0319 $(65,816,624)(131.3)$ & 13 \\
\hline & 4 & 107 & $7.33^{2}$ & ROS0024 $(49,393,863)(81.3)$ & MCW0240 $(67,652,149)(116.0)$ & 257 \\
\hline & 6 & 33 & $5.08^{2}$ & ADL0377 $(27,801,410)(30.9)$ & ADL0142 $(29,295,183)(33.7)$ & 25 \\
\hline \multirow[t]{4}{*}{ Tibia width } & 1 & 86 & $14.14^{3}$ & MCW0297 $(51,632,067)(85.8)$ & LEI0146 $(53,187,445)(90.3)$ & 20 \\
\hline & 1 & 337 & $7.51^{2}$ & LEI0079 $(153,468,487)(331.9)$ & MCW0145 $(157,114,439)(340.3)$ & 26 \\
\hline & 4 & 143 & $9.05^{2}$ & MCW0240 $(67,652,149)(116.0)$ & LEI0063 $(81,169,221)(152.0)$ & 179 \\
\hline & 24 & 116 & $5.09^{2}$ & MCW301 $(4,551,227)(100.0)$ & LEI0069 $(5,029,802)(116.2)$ & 4 \\
\hline \multirow[t]{4}{*}{ Tibia weight } & 1 & 105 & $8.99^{3}$ & LEI0146 $(53,187,445)(90.3)$ & LEI0174 $(62,932,827)(119.8)$ & 171 \\
\hline & 1 & 332 & $12.43^{3}$ & LEI0079 $(153,468,487)(331.9)$ & MCW0145 $(157,114,439)(340.3)$ & 26 \\
\hline & 4 & 138 & $21.20^{3}$ & MCW0240 $(67,652,149)(116.0)$ & LEI0063 $(81,169,221)(152.0)$ & 179 \\
\hline & 13 & 8 & $4.89^{2}$ & ADL0147 $(7,649,069)(0.0)$ & MCW0213 $(9,607,064)(8.4)$ & 63 \\
\hline & 3 & 165 & $11.23^{3}$ & LEI0118 $(59,685,002)(163.4)$ & MCW224 $(76,487,564)(198.1)$ & 215 \\
\hline \multirow[t]{2}{*}{ Weight_BW425 } & 2 & 168 & $7.72^{3}$ & ADL0373 $(66,505,871)(156.0)$ & LEI0096 $(69,807,507)(181.0)$ & 48 \\
\hline & 4 & 139 & $12.67^{3}$ & MCW0240 $(67,652,149)(116.0)$ & LEI0063 $(81,169,221)(152.0)$ & 179 \\
\hline
\end{tabular}

${ }^{1}$ Position from first marker on chromosome. ${ }^{2}$ Significant at $P<0.05$ on chromosome. ${ }^{3}$ Significant at $P<0.01$ on chromosome. ${ }^{4}$ Gallus gallus 4.0 assembly. ${ }^{5}$ Body weight at 42 days (BW42) of age was included as a covariate. 


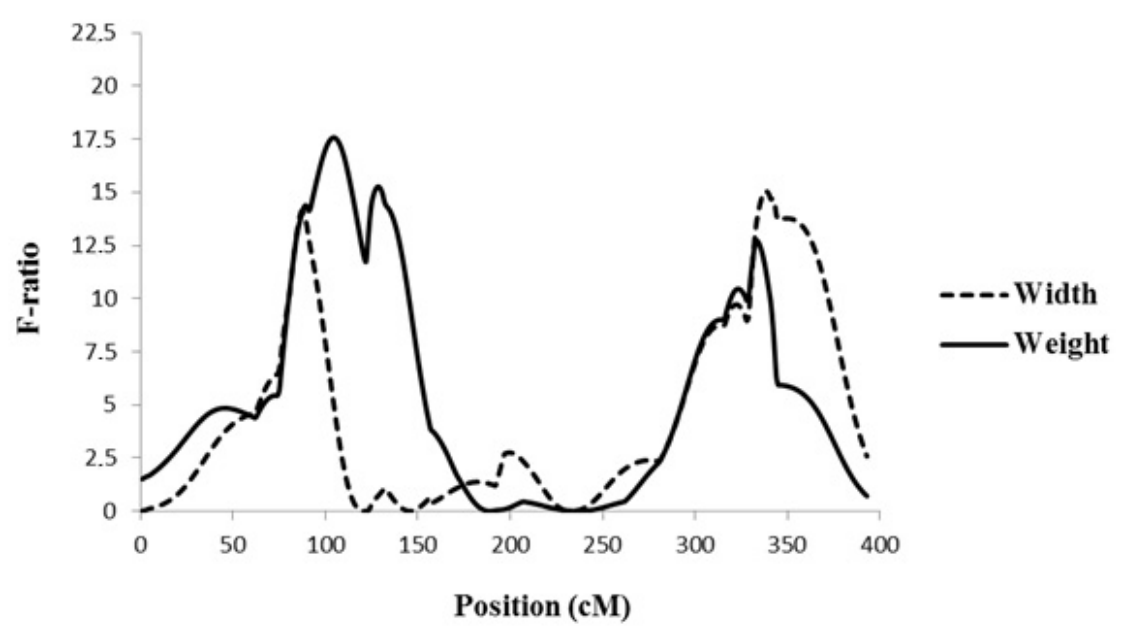

Figure 1. Statistical estimates of F-ratio according to position (cM) for tibia width and weight on GGA1. Tibia width (F test $\left.=7.21^{*}\right)$ and weight $\left(F\right.$ test $\left.=12.43^{* *}\right)$. ${ }^{*} P<0.05 ;{ }^{* *} P<0.01$.

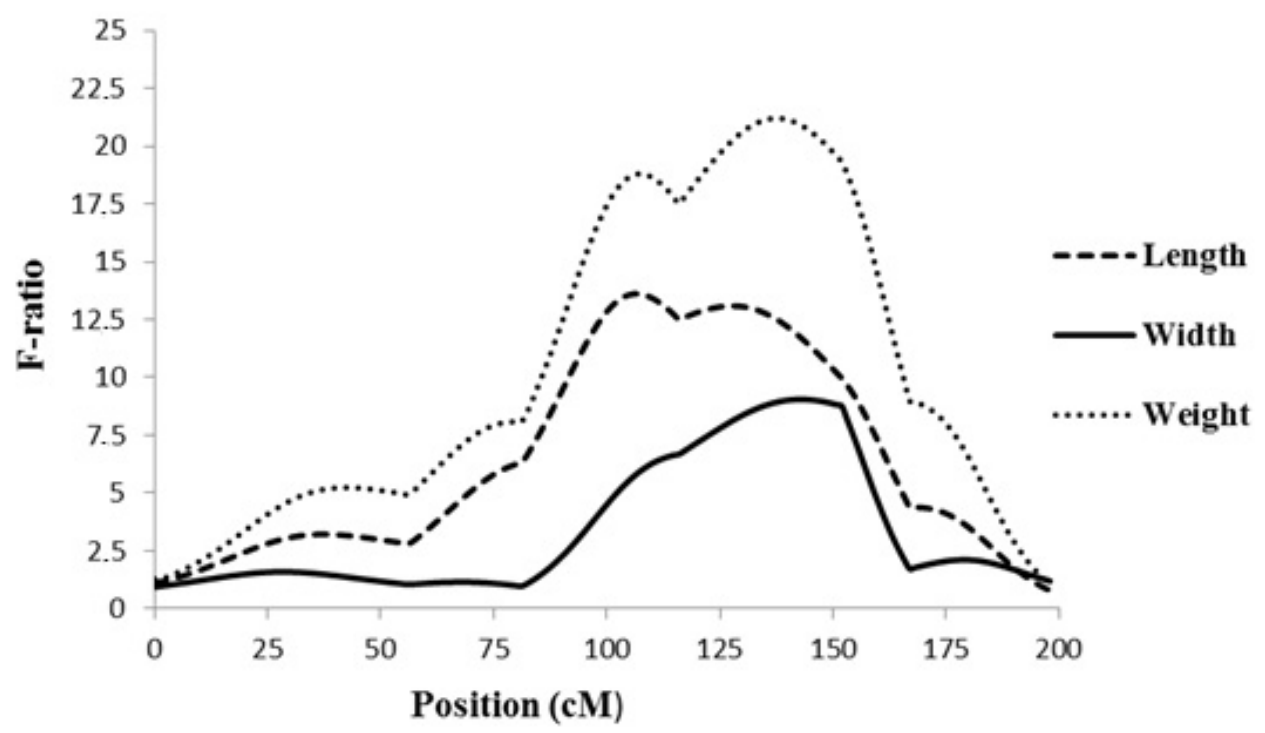

Figure 2. Statistical estimates of F-ratio according to position (CM) for tibia length, width and weight on GGA4. Tibia length $\left(F\right.$ test $\left.=7.33^{*}\right)$, width $\left(F\right.$ test $\left.=9.5^{*}\right)$, and weight $\left(F\right.$ test $\left.=21.20^{* *}\right) .{ }^{*} P<0.05 ;{ }^{* *} \mathrm{P}<0.01$.

A QTL with dominance effect for tibia length was mapped on GGA6, flanked by markers ADL0377 and ADL0142 (Table 4); those with additive and dominance effects for tibia weight and width were mapped on, respectively, GGA13 (ADL0147-MCW0213) and GGA24 (MCW301LEI0069) chromosomes (Table 4). After adjustment for the covariate BW42, two new QTL regions were mapped. The first was mapped for tibia weight between ADL0373 and LEI0096 markers on GGA2; the second for tibia width between LEI0118 and MCW0224 markers on GGA3. These 
regions were not evidenced when the traits were adjusted to BW42 as covariate. Only the QTL region mapped for tibia weight on GGA4 was observed between the same flanking markers (MCW0240-LEI0063) for both analyses (with and without the BW42 as covariate).

\section{DISCUSSION}

\section{Genetic parameters}

Means obtained in this study (Table 1) were lower than those previously reported by Applegate and Lilburn (2002) for a broiler line. Hocking et al. (2009) reported similar means to present study for tibia length, width and weight (Table 1). The results obtained in our study for tibia weight had greater phenotypic variability than other traits; much of this (98\%) was attributed to broiler body weight, according to Applegate and Liburn (2002).

According to heritability estimates for BW42 and tibia bone traits, traits appeared to be responding to selection processes. Regarding heritability estimates, we can infer that there is influence of genes of additive action, which are responsible for genetic variability. De Koning et al. (2003) reported heritability estimates for BW42 and tibia weight in a commercial broiler population that were lower than those observed in our study. Verdal et al. (2013) found higher heritability estimates for tibia weight, length and diameter, compared to those reported in the current study. In our study, the proportion of phenotypic variance due to additive gene effects was higher for tibia length when this trait was adjusted for BW42. Because the artificial selection process in broilers is based on faster weight gain, animals display high body weight on an immature skeleton, which may be responsible for genetic predispositions to skeletal anomalies (Applegate and Lilburn, 2002).

Estimated genetic correlations suggested that traits are either partly controlled by the same genes (pleiotropic genes) or that these genes are in linkage disequilibrium and segregate together, as suggested by Tarka et al. (2010). Hocking et al. (2009) estimated genetic correlations ranging from 0.93 to 0.98 for the same bone traits in chicken of different lines at different ages. In contrast, Verdal et al. (2013) found a negative genetic correlation $(-0.27)$ between tibia weight and length, and virtually no correlation (0.07) between tibia weight and diameter, suggesting that selection for tibia weight did not influence tibia diameter and length.

In the current study, we observed that among tibia bone traits displaying a positive genetic correlation with BW42, tibia length had the lowest genetic correlation with body weight $(0.56 \pm$ 0.17 ) compared to weight and width. Genetic correlation estimates between tibia length, width, and weight decreased when bone traits were adjusted for BW42 as a covariate. Reis et al. (2011) suggested that the fast growth of muscle tissue, particularly breast is not accompanied by bone length growth at the same rate. Likewise, Schmidt et al. (1999) reported that genetic alterations in weight gain in a pure line of broilers were not accompanied by bone strength correlated changes, which could partly explain bone problems in broilers.

Fast bone growth in broilers due to high rates of weight gain does not allow bone tissue to form properly, as there is greater bone deposition in the periosteum. This process is associated with problems such as low mineralization, porosity and altered mechanical properties (William et al., 2004). Bone mechanical properties are determined by minerals, water and organic material (mainly type I collagen), their relative amounts, quality, and arrangement in the bone matrix (Currey, 2003). According to Sorensen (1992), resistance to leg fracture in poultry selected for high yield was lower compared to broilers that had not gone through a selection process, suggesting that broilers selected for growth traits such as body weight may be more likely to have bone disorders. 


\section{Quantitative trait loci mapping}

According to Zhang et al. (2011), QTL mapping is a major approach to detecting genetic variability of economically important traits. Zhang et al. (2010) studied bone traits and identified 12 QTL between LEI0079 and ROS0025 markers on GGA1. In the current study, we mapped a QTL region for tibia width and weight between the LEI0079 and MCW145 markers on GGA1. The gene $D A C H 1$ is mapped on this interval and acts on signaling fibroblast growth factor during skeletal limb development, acting as an intermediate in the metabolic pathway that regulates cell proliferation or differentiation of the fibroblast growth factor (Horner et al., 2002). This gene is also involved in the formation of the apical ectodermal ridge, responsible for the development of the upper and lower limbs during embryogenesis (Kida et al., 2004).

One QTL for tibia weight was mapped between LEI0146 and LEI0174 markers (GGA1). These markers have been previously associated with QTL for tibia plateau angle (Sharman et al., 2007) and femur bone mineral density (Rubin et al., 2007). In this same region, two candidate genes associated with performance traits, fat deposition and carcass percentage are mapped: insulin-like growth factor 1 (IGF1) and lysine (K)-specific demethylase 5A (KDM5A) (Boschiero et al., 2013).

Sharman et al. (2007) also mapped QTL for tibia weight on GGA1, in the region flanked by markers MCW0297 and LEI0146. Nones et al. (2012) mapped QTL for carcass chemical composition on GGA1 using the same population as that used in the current study and they mapped QTL region for fat/dry matter flanked by markers MCW0297-LEI0146 and QTL for fat flanked by markers LEI0146-LEI0174. The highest genetic association in this study was estimated for the tibia width and weight $(0.89 \pm 0.06)$. Thus, identification of the same QTL region for both traits on GGA1 (LEI0079-MCW145) and GGA4 (MCW0240-LEI0063) appears consistent.

The fact that QTL regions for bone traits have been mapped in the same region suggests that the same or a group of linked genes are involved in phenotypic variation of these traits. Likewise, Nones et al. (2006) mapped QTL for carcass and BW42 traits on GGA1, in the same broiler population.

Ambo et al. (2009), studying the same population of broilers, mapped QTL for body weight traits at 35 and 41 days of age on the GGA4, exactly in the same chromosome region where QTL for tibia width and weight were mapped (MCW0240-LEI0063). Within this chromosome region, Baron et al. (2011) mapped QTL for drums and thighs; Schreiweis et al. (2005) for tibia area, length, and width; and Sharman et al. (2007) for tibia bone mineral density, and femur weight.

On GGA6, in the same QTL region identified in this study for tibia length (ADL0377ADL0142), QTL were mapped for body weight at 1 day of age (Ambo et al., 2009) and tibia width (Schreiweis et al., 2005). Sharman et al. (2007) also described a QTL region for the femur weight very close to this QTL region.

In this study, one QTL was mapped for tibia weight on GGA13, between the markers ADL0147 and MCW0213. Markers previously associated with QTL for thigh bone weight have been described in the same chromosome region (de Koning et al., 2004).

Novel QTL were mapped flanked by markers ADL0150-ADL0319 and LEI0079-MCW0145 on GGA1; ROS0302-MCW301 on GGA24; and LEI0118-MCW224 on GGA3. All regions had no previous description associated with bone traits in the literature.

For selection, it is important to find QTL regions with a direct, rather than indirect, effect on the traits of interest through total live weight. Without adjusting BW42 as a covariate, many QTL regions were mapped for these traits nearby regions associated with BW42 in the same population used in this study (Nones et al., 2006; Ambo et al., 2009; Campos et al., 2009; Baron et al., 2011; Nones et al., 2012). When BW42 was included as a covariate in the model, only three QTL were 
mapped: two for tibia weight and another for tibia width (Table 3).

The QTL for tibia weight mapped on 168 cM on GGA2 between markers ADL0373 and LEI0096 was not observed without BW42 as a covariate, probably because the QTL region with the greatest effect was mapped for BW42, or because two QTL regions strongly associated with effects in the same direction tend to present as a single QTL of great effect (Barton and Keightley, 2002). This same chromosome region has been associated with body weight at 35 days of age (Ambo et al., 2009) and with carcass percentage (Baron et al., 2011). The melanocortin-4 receptor gene $(M C 4 R)$, which has been associated with the weights of body, carcass, and leg muscle in broilers, is mapped to this QTL region, and is considered an important candidate gene for carcass traits such as body weight and growth (Qiu et al., 2006).

After adjusting for BW42 as a covariate, one QTL region was also found for tibia width on GGA3, flanked by markers LEI0118 and MCW224. Baron et al. (2011) mapped one QTL region adjacent to this region to percentage of wings, drums, and thighs related to body weight at 42 days of age. There are no reports in the literature describing QTL for bone traits in that chromosome region.

Although there are few studies of QTL regions associated with tibia bone traits, markers associated with QTL regions in other populations corroborated with those reported in the current study, suggesting that these, as well as the new chromosome regions identified here, are important regions for future research of candidate genes and causal mutations. These findings will contribute to a better understanding of how these traits are related, and may contribute to identifying means by which to reduce bone or locomotor problems, which currently cause great economic losses in the poultry industry.

\section{ACKNOWLEDGMENTS}

Financial support was provided by Brazilian Agricultural Research Corporation Swine and Poultry (EMBRAPA) and National Counsel of Technological and Scientific Development (CNPq). Authors B.N.N. Ragognetti and V.A.R. Cruz were supported by a fellowship from Coordination for the Improvement of Higher Education Personnel (CAPES). N.B. Stafuzza was supported by a postdoctoral fellowship from CNPq. T.B.R. da Silva and N.V. Grupioni were supported by a postdoctoral fellowship from CAPES/EMBRAPA. T.C.S. Chud was supported by fellowship from CAPES/ EMBRAPA and São Paulo Research Foundation. D.P. Munari was supported by productivity research fellowship from CNPq.

\section{REFERENCES}

Ambo M, Moura AS, Ledur MC, Pinto LF, et al. (2009). Quantitative trait loci for performance traits in a broiler $x$ layer cross. Anim. Genet. 40: 200-208.

Applegate TJ and Lilburn MS (2002). Growth of the femur and tibia of a commercial broiler line. Poult. Sci. 81: 1289-1294.

Araújo GM, Vieites FM and Souza CS (2012). Importance of bone development in poultry. Arch. Zootec. 61: 79-89.

Baron EE, Moura AS, Ledur MC, Pinto LF, et al. (2011). QTL for percentage of carcass and carcass parts in a broiler $x$ layer cross. Anim. Genet. 42: 117-124.

Barton HN and Keightley PD (2002). Understanding quantitative genetic variation. Nat. Rev. Genet. 3: 11-21.

Boschiero C, Jorge EC, Ninov K, Nones K, et al. (2013). Association of IGF1 and KDM5A polymorphisms with performance, fatness and carcass traits in chickens. J. Appl. Genet. 54: 103-112.

Bradshaw RH, Kirkden RD and Broom DM (2002). A review of the aetiology and pathology of leg weakness in broilers in relation to welfare. Avian Poultry Biol. Rev. 13: 45-103.

Campos RL, Nones K, Ledur MC, Moura AS, et al. (2009). Quantitative trait loci associated with fatness in a broiler-layer cross. Anim. Genet. 40: 729-736.

Churchill GA and Doerge RW (1994). Empirical threshold values for quantitative trait mapping. Genetics 138: 963-971. 
Currey JD (2003). How well are bones designed to resist fracture? J. Bone Miner. Res. 18: 591-598.

de Koning DJ, Windsor D, Hocking PM, Burt DW, et al. (2003). Quantitative trait locus detection in commercial broiler lines using candidate regions. J. Anim. Sci. 81: 1158-1165.

de Koning DJ, Haley CS, Windsor D, Hocking PM, et al. (2004). Segregation of QTL for production traits in commercial meattype chickens. Genet. Res. 83: 211-220.

Gao Y, Du ZQ, Feng CG, Deng XM, et al. (2010). Identification of quantitative trait loci for shank length and growth at different development stages in chicken. Anim. Genet. 41: 101-104.

Gao Y, Feng CG, Song C, Du ZQ, et al. (2011). Mapping quantitative trait loci affecting chicken body size traits via genome scanning. Anim. Genet. 42: 670-674.

Havenstein GB, Ferket PR, Scheideler SE and Larson BT (1994a). Growth, livability, and feed conversion of 1957 vs 1991 broilers when fed "typical" 1957 and 1991 broiler diets. Poult. Sci. 73: 1785-1794.

Havenstein GB, Ferket PR, Scheideler SE and Rives DV (1994b). Carcass composition and yield of 1991 vs 1957 broilers when fed "typical" 1957 and 1991 broiler diets. Poult. Sci. 73: 1795-1804.

Hocking PM, Sandercock DA, Wilson S and Fleming RH (2009). Quantifying genetic (co)variation and effects of genetic selection on tibia bone morphology and quality in 37 lines of broiler, layer and traditional chickens. Br. Poult. Sci. 50: 443-450.

Horner A, Shum L, Ayres JA, Nonaka K, et al. (2002). Fibroblast growth factor signaling regulated Dach1 expression during skeletal development. Dev. Dyn. 225: 35-45.

Kida Y, Maeda Y, Shiraishi T, Suzuki T, et al. (2004). Chick Dach1 interacts with the Smad complex and Sin3a to control AER formation and limb development along the proximodistal axis. Development 131: 4179-4187.

Knowles TG, Kestin SC, Haslam SM, Brown SN, et al. (2008). Leg disorders in broiler chickens: prevalence, risk factors and prevention. PLOS ONE 3: e1545.

Le Bihan-Duval E, Nadaf J, Berri C, Pitel F, et al. (2011). Detection of a cis eQTL controlling BMCO1 gene expression leads to the identification of a QTG for chicken breast meat color. PLoS One 6: e14825.

Meyer K (2007). WOMBAT: a tool for mixed model analyses in quantitative genetics by restricted maximum likelihood (REML). J. Zhejiang Univ. Sci. B. 8: 815-821.

Nones K, Ledur MC, Ruy DC, Baron EE, et al. (2006). Mapping QTLs on chicken chromosome 1 for performance and carcass traits in a broiler x layer cross. Anim. Genet. 37: 95-100.

Nones K, Ledur MC, Zanella EL, Klein C, et al. (2012). Quantitative trait loci associated with chemical composition of the chicken carcass. Anim. Genet. 43: 570-576.

Qiu X, Li N, Deng X, Zhao X, et al. (2006). The single nucleotide polymorphisms of chicken_melanocortin-4 receptor (MC4R) gene and their association analysis with carcass traits. Sci. China C. Life Sci. 49: 560-566.

Reis DTC, Torres RA, Barbosa AA, Rodrigues CS, et al. (2011). Effects of lineage and sex on geometrical and biomechanical properties of broiler chickens tibias. Acta Sci. Anim. Sci. 33: 101-108.

Rubin CJ, Brändström H, Wright D, Kerje S, et al. (2007). Quantitative trait loci for BMD and bone strength in an intercross between domestic and wildtype chickens. J. Bone Miner. Res. 22: 375-384.

Savegnago RP, Buzanskas ME, Nunes BN, Ramos SB, et al. (2011). Heritabilities and genetic correlations for reproductive traits in an F2 reciprocal cross chicken population. Genet. Mol. Res. 10: 1337-1344.

Schmidt GS, Munari DP, Figueiredo EAP, Zanotto DL, et al. (1999). Genetic evolution of pure paternal and maternal broiler lines. Pesq. Agropec. Bras. 34: 623-627.

Schreiweis MA, Hester PY and Moody DE (2005). Identification of quantitative trait loci associated with bone traits and body weight in an F2 resource population of chickens. Genet. Sel. Evol. 37: 677-698.

Seaton G, Hernandez J, Grunchec JA, White I, et al. (2006). GridQTL: a grid portal for qtl mapping of compute intensive datasets. Proceedings of 8th World Congress On Genetics Applied To Livestock Production, August 13-18, Belo Horizonte, Brasil.

Sharman PW, Morrice DR, Law AS, Burt DW, et al. (2007). Quantitative trait loci for bone traits segregating independently of those for growth in an F2 broiler x layer cross. Cytogenet. Genome Res.117: 296-304.

Sørensen P (1992). The genetics of leg disorders. In: Bone biology and skeletal disorders in poultry (Whitehead CC, eds.). Carfax Publishing, Abingdon, UK, 213-229.

Tarka M, Akesson M, Beraldi D, Hernández-Sánchez J, et al. (2010). A strong quantitative trait locus for wing length on chromosome 2 in a wild population of great reed warblers. Proc. Biol. Sci. 277: 2361-2369.

Tsudzuki M, Onitsuka S, Akiyama R, Iwamizu M, et al. (2007). Identification of quantitative trait loci affecting shank length, body weight and carcass weight from the Japanese cockfighting chicken breed, Oh-Shamo (Japanese large game). Cytogenet. Genome Res. 117: 288-295.

Verdal H, Narcy A, Bastianelli D, Même N, et al. (2013). Genetic variability of metabolic characteristics in chickens selected for their ability to digest wheat. J. Anim. Sci. 91: 2605-2615. 
Williams B, Waddington D, Murray DH and Farquharson C (2004). Bone strength during growth: influence of growth rate on cortical porosity and mineralization. Calcif. Tissue Int. 74: 236-245.

Zhang H, Zhang YD, Wang SZ, Liu XF, et al. (2010). Detection and fine mapping of quantitative trait loci for bone traits on chicken chromosome one. J. Anim. Breed. Genet. 127: 462-468.

Zhang H, Liu SH, Zhang Q, Zhang YD, et al. (2011). Fine-mapping of quantitative trait loci for body weight and bone traits and positional cloning of the RB1gene in chicken. J. Anim. Breed. Genet.128: 366-375.

Zhou H, Deeb N, Evock-Clover CM, Mitchell AD, et al. (2007). Genome-wide linkage analysis to identify chromosomal regions affecting phenotypic traits in the chicken. III. Skeletal integrity. Poult. Sci. 86: 255-266. 